\title{
Analyzing the Health Security System in Japan: Lessons Learned for Bangladesh
}

\author{
Muhammad Kawsar Mahmud \\ Counseling and Placement Center, Bangladesh University of Professionals, Dhaka, Bangladesh \\ Email:mahmud@bup.edu.bd
}

How to cite this paper: Mahmud, M.K. (2020) Analyzing the Health Security System in Japan: Lessons Learned for Bangladesh. Open Access Library Journal, 7: e6227. https://doi.org/10.4236/oalib.1106227

Received: March 13, 2020

Accepted: May 26, 2020

Published: May 29, 2020

Copyright () 2020 by author(s) and Open Access Library Inc.

This work is licensed under the Creative Commons Attribution International License (CC BY 4.0).

http://creativecommons.org/licenses/by/4.0/ (c) (i) Open Access

\begin{abstract}
Bangladesh has achieved tremendous success in health sector. Despite remarkable achievements in health security is still a concern for the nation. Most of the people still live in village and grope to receive better health services around them. However, they don't have scope to consult with anticipated doctors aside from coming in any city. On the other hand, medical expenses are quite high that puts pressure on them. This article explores Japanese' experience in designing and implementing effective mechanism and policies for better health service and extracts lessons from them to suggest some policy measures that Bangladesh may consider in its effort to ensure quality and affordable health service. This study applies qualitative research methodology and collects data from secondary sources. This study found that all citizens of Japan have to come under any insurance policy to receive health services that results bills are paid under copayment system. The government also sets all prices centrally that is why no one can increase or decrease any medical expenses. This study also found that payment portion for medical expenses being changed based on ages that leave the scope for the citizen to receive health service under a convenient and affordable condition. These initiatives together with other supporting attempts would help Bangladesh achieve better health service.
\end{abstract}

\section{Subject Areas}

Health Policy, Public Health

\section{Keywords}

Health Service, Insurance, Out of Pocket Money, Patients, Payment

\section{Introduction}

According to the WHO Constitution, "the health of all peoples is fundamental to 
the attainment of peace and security and is dependent upon the fullest co-operation of individuals and States."

Health security is the global challenge in the world. Many people are constantly infected with various diseases while many of them are dying. Most of the people can't consult with doctor either due to doctor's shortage or lack of money. In Somalia, some 1.5 million Somalis have lost access to healthcare service over the last two years as 10 hospitals have closed or cut back their services due to aid shortages (Migiro, 2016) [1]. In Kenya, millions of Kenyans cannot afford medical expenses at public or private clinics (World Bank, 2014) [2]. In India, it requires over 10 times more allopathic doctors to meet World Health Organization (WHO) prescribed norms for the doctor-population ratio (Chandna, 2018) [3]. The very shocking condition exists in Zimbabwe where hospitals have been without basic supplies which badly needed to provide health facilities to the people. Health workers frequently strike because of unpaid wages and unfavorable working condition there (Muronzi, 2019) [4]. Every day, 170 young people are infected with HIV in West and Central Africa, and many can't bear the cost of treatment (O'GRADY, 2018) [5]. According to the International Agency for Research on Cancer (IARC) survey, some 12,764 new breast cancer patients are detected every year while the number of deaths from breast cancer is 6846 in Bangladesh (Hasan, 2018) [6]. According to the International Agency for Research on Cancer (IARC) survey, 7.5 per cent of the people currently in Bangladesh are affected due to cancer. If this condition continues, it will exceed 13 percent by 2030 (Chaity, 2017) [7]. In China, the government conducted various reforms including the expansion of social health insurance, the reform of public hospitals, and the strengthening of primary care that has attained praiseworthy success. The Chinese government declared the "Healthy China 2030" blueprint in October 2016, which has the goals of providing universal health security for all citizens by 2030 ( $\mathrm{Li} \& \mathrm{Fu}, 2017$ ) [8].

Japan has been an exemplary to rest of the world in term of providing health service to its citizen. Japan introduced a universal health coverage system in 1961. Since that time, all citizens require joining the public health insurance scheme to receive health service with paying a certain percentage which is settled based on ages, income, etc. (Otake, 2016) [9]. That results in the standard of living and average life expectancy has started increasing with the passage of time. The average life expectancy in Japan was 81.25 years for men and 87.32 years for women in 2018, the highest figures ever recorded. When statistics were first collected in 1947, life expectancy was 50.06 years for men and 53.96 years for women. Since then, huge advances in treating disease, along with the public's rising health awareness, have contributed to the population's ever-lengthening lifespan (Nippon, 2019) [10].

Health system in Bangladesh is pluralistic where government, the private sector, NGOs and donor agencies play a vital role as the key actor. A patient had to pay most of the medical expenses by out of pocket money which is really unaf- 
fordable for the poor. Most of the people still live in the village and health facilities are inadequate to their surroundings. Healthcare expenditure is unpredictable which has a negative impact on the poor. Medical expenses vary from hospital to hospital, especially in private hospitals. Besides, government hospitals have a lack of various insufficiencies (BDHSR, 2015) [11]. Patients are going to abroad for taking health service. Only 75,688 patients traveling to India for health care in 2010 the figure has risen to 134,344 in 2015 and 201,333 in 2016 (bdnews 24, 2017) [12]. Above all these, Bangladesh has made great strides in improving the health of its population, much more than a country at its level of development can be expected to do (Chowdhury \& Osmani, 2010) [13].

The main purpose of this research is to compare the differences between Bangladesh and Japan health service system with various dimensions so that Bangladesh can take lessons considering the Japanese experiences. Once the comparisons are explained precisely, it will be easier to develop a better health care system for this country. It is expected that the outcome of the study will give insightful knowledge to the people and policymaker to consider these issues to ensure the best service for the people.

\section{Literature Review}

There is a profusion of literature on Japan and Bangladesh health service but did not find anyone on the comparison between these two countries. The reviewed books, articles, papers and reports have discussed different aspects of health policy and health system.

Health is now universally considered as an important index of human development (Mannan, 2013) [14]. Japan has made a remarkable success in healthcare. Japan health policy had started in 1922 but this policy moved through various reforms continuously. In 1961, Japan introduced a universal health coverage system for all citizens that made opportunity to enroll under any health insurance scheme and pay medical expenses in a copayment system (Fukawa, 2002) [15]. Medical fee schedule is also revised in Japan every two years which sets the prices of drugs, devices, etc. To revise this price, a committee is formed with the inclusion of governmental representatives, physicians, neutral members and so on. The Japanese healthcare system has been cost efficient (Uetsuka, 2012) [16]. Any bills of medical expenses are submitted to the selected offices to examine discrepancies. Japan also opened schemes for elderly people with $10 \%$ copayment during taking services (Fukawa, 2002) [15]. In a comparative study between Japan and Portugal, it has found that Japan population has the highest level of satisfaction in their health sector than Portugal. As the reason, it has been identified that financial support from insurance premium, public fund and co-payment that became so easy for the patients to receive health service. Besides, co-payment rate is not high in Japan (Barata, Tokuda \& Martins, 2012) [17]. On the other hand, health care is a big challenge in Bangladesh. Some challenges like absenteeism, corruption, shortage of doctors/nurses; inefficiency and 
mismanagement hinder to provide best services to the patients (Mahmood, 2012) [18]. Although the government of Bangladesh spends considerable amounts of resources to ensure health service, but discontentment is often expressed over the in availability and quality of these services. In terms of Bangladesh, economic in accessibility is the major barrier to receive good health services for the poor and woman (Mannan, 2013) [14]. The poor suffer much to take health care services under their affordable limit. Bangladesh has a shortage of physicians and nurses along with the absence of good technology (Mahmood, 2012) [18]. According to the World Health Organization (WHO 2010) [19] only about $3 \%$ of the Gross Domestic Product (GDP) is spent on health services. However, government expenditure on health is only about $34 \%$ of the total health expenditure (THE), the rest (66\%) being out-of-pocket (OOP) expenses. s. Inequity, therefore, is a serious problem affecting the health care system (Islam, Ahsan \& Biswas, 2015) [20]. On the other hand, infectious diseases and communicable diseases are the main public health issues in South-East Asia. Bangladesh is one of the countries located in this region and has improved remarkably over the past three decades. Nevertheless, Bangladesh faces momentous health challenges. A study was performed according to York methodology to find out the major public health issues and challenges in Bangladesh. Child malnutrition is one of the major problems in Bangladesh. Besides, Contamination diseases, food contamination and so on are another major problem in Bangladesh. Bangladesh is among the top ten countries in the world in terms of the highest TB burden. Many young children die due to Pneumonia and other infections. Moreover, only $1 \%$ of the population is reported to be HIV-positive. Some common non-communicable diseases like chronic diseases, cancer, diabetes, cardiovascular diseases, and chronic respiratory diseases are also gradually increasing in Bangladesh. Sanitation management is very poor in rural areas (Muhammad, Chowdhury, Arifuzzaman \& Chowdhury, 2016) [21]. The literature has reviewed the health system in Bangladesh and Japan here. This kind of research is pertinent to Bangladesh. No research is found on it, so this paper is dedicated to fulfilling this gap by investigating the health system.

\section{General Objective}

1) To analyze the key determinants of Japan health systems that have been assisted to improve the highest average life expectancy in the world.

2) To provide recommendations in light of Japan experience in order to making time viable and long-sighted plan in Bangladesh.

\section{Methodology}

This study follows the qualitative method where data have been collected from secondary sources. As secondary sources, different government documents, article, journal, newspapers, reports, periodical, video etc. have been consulted from both print and online sources. The researchers have also browsed several 
websites including those of relevant ministries and government offices, and academic journals. However, this is more to be descriptive research. This research is a comparative study which has extensively discussed the health system between Bangladesh and Japan. The aim of the comparative analysis is to identify the strengths of Japan health service that can be applied in Bangladesh.

\section{Healthcare Service System in Bangladesh and Japan: An Overview}

Pluralistic health system prevails in Bangladesh where the Government, the private sector, NGOs and donor agencies are the key four key factors that define its structure and function. The Public sector is the main actor who sets policy and regulation constitutionally. It also recruits health staff and finance in the health sector. The Ministry of Health and Family Welfare in Bangladesh manages District Hospitals, Upazila Health Complexes, Union Health and Family Welfare Centre, and community clinics at ward level through Directorate General of Health Services (DGHS) and Family Planning (DGFP). Since 1976, along with government, the private sectors and NGOs have established a network to provide service in the health sector. NGOs are considered as the 'third sector' which managed $9 \%$ of total health expenditure in 2007 and 6\% in 1998. Most of the NGOs provide not-for-profit services to the underserved population. The Private sector provides mostly for-profit-based service and very few for-not-profits based (BDHSR, 2015) [11]. On the contrary, the Ministry of Health, Labor and Welfare (MHLW) in Japan is the central body to set rules and formulate policies including the health insurance system. Health care system of Japan is characterized at a relatively low cost, covered by universal insurance coverage through social insurance premium and tax subsidies, with virtually free access to health-care facilities. The government of Japan controls and regulates almost health aspects at three levels: national, prefectural, and municipal, where service delivery and implementation are mainly handled by prefectural. Across the 47 prefectures, there are a total of 1718 municipalities. There are three types of municipalities in Japan: cities, towns and villages. The Ministry of Health and Welfare and the Ministry of Labor merged in 2001 to give a better effort. The government also set prices for all which everyone complies with this rule (JHSR, 2018) [22].

\section{Health System of Bangladesh and Japan: A Comparative Analysis}

The provision of basic health services in Bangladesh is a constitutional obligation of the Government. Article 15 of the Constitution stipulates that it shall be a fundamental responsibility of the State to ensure the basic necessities of life, including food, clothing, shelter, education and medical care for its citizens. In addition, Article 18 of the Constitution states that the State shall raise the level of nutrition of its population and improve public health as some of its primary du- 
ties (Rahman, 2017) [23]. Article 25 of the Japanese Constitution fundamentally supports patient rights in Japan, by stating that "all people shall have the right to maintain the minimum standards of wholesome and cultured living. In all spheres of life, the State shall use its endeavours for the promotion and extension of social welfare and security, and of public health." Although there is no basic law determining patients' right in Japan, Article 25 of the Constitution is the basis for every type of health-care policy in Japan (JHSR, 2018) [22].

\subsection{Healthcare Financing}

The medicinal services financing framework in Bangladesh is overwhelmed for the most part by out-of-pocket payments. $67 \%$ health expenditure originates out of pocket payment of total health expenditure, which is considerably higher than that of the world average of 32 percent (Palma, 2018) [24]. The out of pocket payment is the largest source of health financing in Bangladesh (Islam, Ahsan \& Biswas, 2015) [20]. According to the latest Bangladesh National Health Accounts, Bangladesh spends 2.3 billion on health or 16.20 dollar per person in each person in each year, of which, almost two-thirds comes from out-of-pocket payments (BDHSR 2015) [11]. A study conducted by the International Centre for Diarrhoeal Disease Research, Bangladesh (ICDDR, B) found that the out of pocket payment health expenditure pushes four to five million Bangladeshis into destitution (Palma, 2018) [24]. Throughout the years, government financing in the health sector has been increased. Bangladesh spends a lower percentage of GDP on health (Islam, Ahsan \& Biswas, 2015) [19]. Alongside, the private sector also is funding to provide health services, but the cost of services is unaffordable to many poor people in Bangladesh. Donor financing is another important source in Bangladesh health sector. Some donors pool their funds and channel that through the government system, which is known as Reimbursable Project Aid. Besides the pool funders, there are other funding agencies that spend money either directly or through the project, not channeled through the government system (BDHSR, 2015) [11]. Japan health care system, on the other hand, is based on various insurance systems with tax subsidies and some amount of out-of-pocket payment. According to the WHO Global Health Expenditure Database, total health expenditure as a proportion of GDP increased from 7\% in 1995 to $10 \%$ in $2014.84 \%$ health expenditure has come from public sources in 2014 and remaining 16\% from private sources. Out of pocket payment in Japan is relatively low and it has declined from $16 \%$ in 2000 to $14 \%$ in 2014. Japan government centrally regulates drug and medical equipment prices. This price fixes every two years. If the price increases, it impacts on the whole population. So, it is crucial to discuss among the committee members to set new prices. It is mandatory for all hospitals and clinics to abide by the nationally uniform fee schedule which is set by the MHLW (Uetsuka, 2012) [16]. Though there is no such framework in Bangladesh, the government sets sector-wise new prices. The government and institutional support are not at the expected level to ensure. 


\subsection{Payment Mechanism for Medical Expenses}

Copayment system prevails for medical expenses in Japan where the insurance pays a certain proportion and the insured person pays the rest of the portion. Payment proportion varies in accordance with ages, professions, income etc. The proportion of cost-sharing is consistently directed by law. Pre-school infants pay $20 \%$, school-age children through adults up to 69 years old pays $30 \%$ and adults aged from 70 to 74 -year-old pays $10 \%$ while the insurance pays the rest of the portion. Whenever a patient pays bills fallowing taking service, this bill is scrutinized by the centrally regulated authority to find whether any looking at mistakes, excessive utilization, and fraud exists (Fukawa, 2002) [15]. Government employees receive a certain amount of money as medical allowance. In addition to it, a certain payment deducts from each monthly salary for group insurance and benevolent fund, so that; someone claims a big total for expensive medical treatment once in a lifetime period.

\subsection{Large Scale Insurance Policy}

In 1961, Japan started a universal health coverage system that enrolls all citizens under any insurance policy to receive services at a relatively low cost (Kobayashi, 2009) [25]. All residents of Japan must be enrolled in health insurance coverage but foreigners in Japan also can enroll under any insurance if they stay in Japan for a certain time. Employees' Health Insurance and National Health Insurance are two types of major insurance in Japan. Employees' health insurance covers public servants or works in companies, while National Health Insurance covers the self-employed, unemployed, freelancer, retired persons, students and farmers. Employees' Health Insurance is further divided into four major categories such as Japan Health Insurance Association (JHIA), Society Managed Health Insurance (SMHI), Mutual Aid Association, and Seamen's Insurance (JHSR, 2018) [22]. There is no such health policy in Bangladesh centrally which may play a vital role to reduce medical cost. The government of Bangladesh has formulated a healthcare financing strategy for its population. The aim of this strategy is to move toward universal health coverage for its population by 2032. The strategy has three objectives: 1 ) improve equity of healthcare services 2 ) improve access to healthcare services and 3) enhance the efficiency of the health system. Government employees get some insurance facilities in small scale. Some private companies also started health insurance facilities for their employees. Everybody in Japan is compelled to enroll in any medical scheme and paying the premium set by the government. But such a system does not exist in Bangladesh (BDHSR, 2015) [11].

\subsection{Healthcare Service for Elderly People}

The ageing population in Japan is increasing continuously. That is why the demand for healthcare services is forever increasing. So, ensuring a high quality of services for ageing people becomes the main task for health service provid- 
er/local and regional governments. It is expected that the proportion of older people will be $39.4 \%$ in 2055. In 2000, Long-term care insurance (LTCI) was launched in Japan. It is a mandatory program that provides benefits for longterm care for older persons, although which was opposed by the younger persons. For this service, every aged people have to pay $10 \%$ of payment while the remaining portion will pay the insurance. The Japan government has introduced home service to elderly people (JHSR, 2018) [22]. On the other hand, there is any no long-term care service in Bangladesh now. The government allocated BDT 8.91 billion in 2011-2012 to provide old age allowance for senior citizens, and people who have various disabilities like handicaps, physical infirmities and partial handicaps have. Immediate families are taken care of elderly people in Bangladesh. Family members will provide care for the elderly, disabled and chronically ill persons. In the perspective, the parliament passed the 2013 Parents' Care Act in October 2013. This is an unprecedented law mandating that children have to help their elderly parents financially if their parents live separately. The children who will violate this law will face a three-month sentence or a fine (US\$1280) (BDHSR, 2015) [11].

\subsection{Health Service for Disabled People}

The Japan government introduces some very effective system for those who are with different physical disabilities. In this perspective, the government introduced "Assistance Dogs" for various disabled persons by the name of "guide dogs", "hearing dogs", and "service dogs" who will assist persons to move here and there, to hear, to see etc. all dogs must receive special training. The dog also helps the person to call a taxi or to buy goods in the departmental shop (MHLW). 815,000 people with disabilities get a monthly allowance from the government in Bangladesh now. The government has enacted the Disability Welfare Act and the Neurodevelopment Disability Protection Trust Act in 2013 to provide an allowance to the disabled people. In the meantime, the government has MADE a map and found 1.51 million people with disabilities live in the country. The government is expected to provide every disabled people with a monthly allowance in future (Farhin, 2018) [26].

\subsection{Awareness Campaign for Better Health}

The government in Bangladesh conducts various awareness programmes time to time related to health to make the people aware with a view to uprooting any diseases. During spread out of chikunguniya, a mosquito-borne viral disease, the government commenced a mass awareness campaign against this to enroll everyone to eradicate diseases. Thus, such disease uproots remarkably. The Ministry of Health and Welfare of Japan distributed Handbook of mothers and children in 1947 for the first time to provide various health related information for each house to follow it for better health. This 20-paged handbook included registration, maternal care, deliveries, health checkup of the child, and food rations. 
This book was upgraded in 2002. It comprised of 49 pages as a national version. The local government has the opportunity to add local information according to their own needs (Nakamura, 2010) [27]. Japan selected 28 hospitals foreigner friendly, most of the hospital locates in Tokyo. The entity also sets up an English website for non-Japanese to search for hospitals that fulfill their needs (Japan times, 2017) [28]. On the other hand, the website of the Ministry of Health and Family Welfare of Bangladesh contains inadequate information on health. Even medical service providers of all categories are also hesitant to supply the required data to their patients (BDHSR, 2015) [11]. The Ministry of Health, Labor and Welfare (MHLW) of Japan keep most of the health- and welfare-related information updated for the patients. Public comments on various health-care related issues which are very much popular in Japan, even they are encouraged to propose ideas and recommendations on health-care policies and strategies formulated by the MHLW. Health, medical care, health insurance, Pharmaceuticals and Medical Devices, Health and Welfare Services for the persons with disabilities, etc. information is available to the website of Japan. Required information, notice for patients and all updated with sufficient data are available to the website (MHLW). Referral system is an effective means to ensure a close relation among all levels of the health system. It also helps in making cost-effective use of hospitals and primary health care services. In Bangladesh, there is no structured referral system that is why patients with minor problem directly present to hospital for treatment. Patients consider their affordability, accessibility to receive health service. Patients at first contact with pharmacy or village doctor or the community health worker but affluent patients choose the qualified private providers (BDHSR, 2015) [11]. In Japan, referral system is very much effective. Patients receive healthcare from anywhere as there is no gatekeeper but have sufficient opportunity to take refer to consult with the physicians. In somewhere, patients have to pay additional fees if they do not bring referral letter (JHSR, 2018) [22].

\subsection{Punishment for Crime in Medical and Medicine}

It is unknown to outside Japan how Japanese legal and social institutions handle medical errors. They assigned an attorney for the health care related case and insurance related case to solve these sorts of cases in a rush (Leflar, 2009) [29]. Some anomalies in the health system of Bangladesh like a wrong prescription, wrong doses of medicine, wrong or faulty medical equipment, wrong diagnosis, medical corruption, outdated medicines, and lack of quality care and so on. When the above wrongdoers are brought to attention, the authorities then show some reasons like lack of technical competence, poor waste management, Shortage of Doctors, Nurses and technicians, Lack of legal knowledge of the Doctors, Nurses, Technicians and Hospital Managers (Joy, 2011) [30]. In Bangladesh, there is no particular law on medical negligence except some scattered references like several medical codes, ethics, civil and criminal statutes and some constitutional articles (Karim, Goni \& Murad, 2013) [31]. The mobile court at 
times caught some doers who committed crimes and fined them. Some hospitals also find a huge amount of money for selling unapproved and counterfeit medicines and using time-expired reagent in pathological tests (Bdnews 24, 2018) [32].

\subsection{Emergency Health Service and Quality of Services}

Emergency care is delivered at different levels in Bangladesh. Emergency transport services like ambulance are also available in public health facilities but it is not up to the mark. There is no system in Bangladesh which centrally regulates ambulance services. Along with public sector, private sector enterprises are also provided emergency transport facilities. Ad-Din has some small ambulances which carry pregnant women with Dhaka City waited for a call to turn up in the desired location. Air ambulance is also being offered by some renowned hospitals like Square and Apollo. Anjuman Mofidul Islam and Markajul Islam are two nonprofit organizations which provide free emergency transport facilities and also dead bodies (BDHSR, 2015) [11]. In Japan, The Ministry of Internal Affairs and Communications (MIC) is responsible for providing pre-hospital care, while the MHLW is responsible for providing emergency care at health care facilities. Some major challenges for providing emergency care in Japan is: increasing of ageing population along with overutilization of ambulance services, the quality of pre-hospital emergency care and the still-low survival rate of out of hospital cardiac arrests. In 2000, "child emergency phone services \#8000" was established for public pediatric emergency telephone consultation service. Telephone consultancy was increased remarkably to provide health services. In 2011, it reached about 53 million consultations, of which one quarter was supposed to require emergency room visits (MHLW). Dialing 119 for fire and ambulance in Japan but there may be not an English speaker. Consultation with the doctor in Japan is very easy, which needs to carry the card. The physicians are given sufficient time for the patients to provide services. It is also seen the aged persons are spending more times than others to the hospital (Murai, 2017) [33]. In addition, generally, Japanese hospitals are well-equipped with highly advanced technological devices such as computed tomography (CT) and magnetic resonance imaging (RI) scanners. In Bangladesh, medical services are too high. Private hospitals are profit taker. At time fake medicine and normal company medicine also provide to the patients. Unnecessary lab test made them impatient. Some patients died during operations and some patients died due to lack of services (JHSR, 2018) [22]. According to a global study published in an online British medical journal BMJ open that Bangladeshi physicians see patients on an average of 48 seconds (Financial Express, 2017) [34]. Most of the doctors are absent from their workplace, as they show a keen interest in the urban area (Dhaka Tribune, 2017) [35].

\section{Conclusions and Recommendations}

This study explored health service system of Japan and identified some key de- 
terminants that lessons can be learned and implemented in Bangladesh. This study reveals that Japan citizens invite all people to receive health service under an affordable condition. The focal points of analysis in this study include copayment system, out of pocket money, health care for elderly people, Dog Assistance for disabling and so on. In a word, Japan has attained tremendous progress in health service and become an exemplary country in the world. Japanese health service system may be deeply and critically analyzed for ensuring affordable health service system in Bangladesh. The research may put in the new idea to policymakers and help them to find out a solution to have a positive outcome. These initiatives would help Bangladesh to ensure health security. Analyzing the research findings, following are some of the recommendations made for policy implications:

- All types of fees like doctor's consultation fees, medical test fees, medical costs etc. may be regulated centrally.

- Design to reduce out of pocket payment rate to scale down burden from the patient.

- Develop a copayment system of medical expenses to encourage everyone to receive health service.

- Publish a health book directive and may be given to each family.

- Introduce health service for the elderly in each Upazila level.

- Medical expenses may be reduced for the ageing society and the children.

- Encourage for non-profit health services.

- Strick punishment may be applied to fake medicine producer and charge for extra amount by the name of service.

- Encourage to setup modern technology-based hospital.

- Introducing Assistance Dogs service for disabled people.

- Website should be updated time to time.

- More health campaign may be conducted in rural area.

\section{Conflicts of Interest}

The author declares no conflicts of interest regarding the publication of this paper.

\section{References}

[1] Migiro, K. (2016) Aid Cuts Trigger Health Crisis in Somalia, Say Relief Agencies. http://www.daily-sun.com/post/287740/Bangladesh-exports-medicines-to-145-coun tries-across-globe

[2] World Bank (2014) Improving Health Care for Kenya's Poor. http://www.worldbank.org/en/news/feature/2014/10/28/improving-healthcare-for-k enyas-poor

[3] Chandna, H. (2018) Just 1 Doctor to Treat 11,000 Patients: The Scary Truth of India's Govt. Healthcare.

https://theprint.in/india/governance/just-1-doctor-to-treat-11000-patients-govt-rep ort-details-indias-health-crisis/74013/

[4] Muronzi, C. (2019) Zimbabwe Doctors Strike over Poor Wages and Working Con- 
ditions.

https://www.aljazeera.com/news/2019/09/zimbabwe-doctors-strike-poor-wages-wor king-conditions-190904102437057.html

[5] O’Grady, S. (2018) Every Day, 170 Young People Are Infected with HIV in West and Central Africa, and Many Can't Afford Treatment. https://www.latimes.com/ https://www.latimes.com/world/la-fg-africa-aids-20180402-story.html

[6] Hasan, M. (2018) Social Taboo Leading Cause for Unchecked Breast Cancer in Bangladesh. https://www.dhakatribune.com/ https://www.dhakatribune.com/bangladesh/event/2018/10/27/social-taboo-leadingcause-for-unchecked-breast-cancer-in-bangladesh

[7] Chaity, M.K. (2017) Bangladesh Severely Unequipped to Treat Cancer.

https://www.dhakatribune.com/bangladesh/2017/02/04/bangladesh-severely-unequi pped-treat-cancer

[8] Li, L. and Fu, H. (2017) China's Health Care System Reform: Progress and Prospects. The International Journal of Health Planning and Management, 32, 240-253. https://doi.org/10.1002/hpm.2424

[9] Otake, T. (2016) How Japan Is Tweaking the Cost of Health Care. https://www.japantimes.co.jp/news/2016/02/17/national/social-issues/japan-tweaki ng-cost-health-care/\#.W6J5ZVUzbIW

[10] Nippon (2019) Life Expectancy for Japanese Men and Women at New Record High. https://www.nippon.com/ https://www.nippon.com/en/features/h00250/life-expectancy-for-japanese-men-an d-women-at-new-record-high.html

[11] World Health Organization Regional Office for the Western Pacific (2015)|'Bangladesh Health System Review. WHO Regional Office for the Western Pacific, Manila. https://apps.who.int/iris/handle/10665/208214

[12] bdnews24 (2017) Bangladeshis Are Largest Foreign Takers of Indian Health Services: Report. Dhaka.

https://bdnews24.com/health/2017/04/26/bangladeshis-are-largest-foreign-takers-of -indian-health-services-report

[13] Chowdhury, O.H. and Osmani, S.R. (2010) Towards Achieving the Right to Health: The Case of Bangladesh. The Bangladesh Development Studies, 33, 205-273. https://bids.org.bd/uploads/publication/BDS/33/33-1\&2/05 Omar H \& S R Osm ani.pdf

[14] Mannan, M.A. (2013) Access to Public Health Facilities in Bangladesh: A Study on Facility Utilisation and Burden of Treatment. Bangladesh Development Studies, 36, 25-80.

[15] Fukawa, T. (2002) Public Health Insurance in Japan. World Bank Institute, Washington DC.

[16] UETSUKA (2012) Characteristics of Japan's Healthcare Systems and the Problems. https://www.med.or.jp/english/journal/pdf/2012 04/330 333.pdf

[17] Barata, A.N., Tokuda, Y. and Martins, H.M.G. (2012) Comparing Healthcare Systems: Considering Japan and Portugal. Revista Portuguesa de Saúde Pública, 30, 180-192. https://doi.org/10.1016/j.rpsp.2012.10.003

[18] Mahmood, S.A.I. (2012) Health Systems in Bangladesh. Health Systems and Policy Research, 1, 1-4.

[19] Constitution of the World Health Organization. http://origin.searo.who.int/about/constitution/en/ 
[20] Islam, A., Ahsan, G.U. and Biswas, T. (2015) Health System Financing in Bangladesh: A Situation Analysis. American Journal of Economics, Finance and Management, 1, 494-502.

[21] Muhammad, F., Chowdhury, M., Arifuzzaman, M. and Chowdhury, A. (2016) Public Health Problems in Bangladesh: Issues and Challenges. South East Asia Journal of Public Health, 6, 11-16. https://doi.org/10.3329/seajph.v6i2.31830

[22] Sakamoto, H., Rahman, M., Nomura, S., Okamoto, E., Koike, S., et al. (2018)|Japan Health System Review. World Health Organization. Regional Office for South-East Asia. https://apps.who.int/iris/handle/10665/259941

[23] Rahman, B. (2018) Community Clinic in Bangladesh: Taking Health Services to Rural People.

https://www.daily-sun.com/printversion/details/265214/2017/10/31/Community-Cl inic-in-Bangladesh:Taking-Health-Services-to-Rural-People

[24] Palma, P. (2018) Health Sector Uncared for. https://www.thedailystar.net https://www.thedailystar.net/frontpage/2018-19-bangladesh-budget-health-sector-u ncared-1588216

[25] Kobayashi, Y. (2009) Five Decades of Universal Health Insurance Coverage in Japan: Lessons and Future Challenges. Japanese Society of Public Health, 52, 263-268.

[26] Farhin, N. (2018) Allowance for All Disabled People from Next Year. https://www.dhakatribune.com/bangladesh/law-rights/2018/02/28/allowance-disabl ed-people-next-year/

[27] Nakamura, Y. (2010) Maternal and Child Health Handbook in Japan. International Medical Community, 53, 259-265.

[28] Japantimes (2017) 28 Hospitals around Japan Selected as Friendly to Foreign Visitors.

https://www.japantimes.co.jp/news/2017/02/20/national/science-health/28-hospital s-around-japan-selected-friendly-foreign-visitors/\#.W6JVjFUzbIW

[29] Leflar, R.B. (2009) The Regulation of Medical Malpractice in Japan. Clinical Orthopedics and Related Research, 467, 443-449. https://doi.org/10.1007/s11999-008-0602-Z

[30] Joy, B.H. (2011) Healthcare Laws in Bangladesh. https://www.scribd.com/doc/67389243/Healthcare-Laws-in-Bangladesh-Final

[31] Karim, S.M.T. Goni, M.R. and Murad, M.H. (2013) Medical Negligence Laws and Patient Safety in Bangladesh: An Analysis. Journal of Alternative Perspectives in the Social Sciences, 5, 424-442. https://www.japss.org/upload/8.\%20Karim.pdf

[32] bdnews24 (2018) Apollo Hospitals in Dhaka Fined for Selling Counterfeit Drugs, Keeping Expired Reagents. https://bdnews24.com/bangladesh/2018/02/19/apollo-hospitals-in-dhaka-fined-forselling-counterfeit-drugs-keeping-expired-reagents

[33] Murai, S. (2017) Agency Seeks to Deter Nonemergency 119 Calls. https://www.japantimes.co.jp/news/2017/01/05/national/agency-seeks-deter-nonem ergency-119-calls/\#.W6SPclUzbIU

[34] Financial Express. Doctors in Bangladesh See Patients for Merely 48 Seconds on Average, Reveals Study.

https://thefinancialexpress.com.bd/health/doctors-in-bangladesh-see-doctors-for-m erely-48-seconds-on-average-reveals-study-1510301628

[35] Dhaka Tribune. PM Hasina Tells Govt Doctors to Stay at Workplace or Quit Job. https://www.dhakatribune.com/health/2017/12/28/pm-asks-govt-doctors-to-stay-w orkplace-or-quit-job 